\title{
Study of Job Burnout of Employees Working in a Leading IT Company of Central India
}

\author{
${ }^{1}$ Dr. Ruchi Sao, ${ }^{2}$ Prof. Shravan Chandak, Dr. Amir Khan \\ ${ }^{1-3}$ Assistant Professor, Shri Ramdeobaba College of Engineering and Management, Nagpur \\ Email:saorn@rknec.edu,chandaksj3@rknec.edu,khanah@rknec.edu
}

\section{Received: $20^{\text {th }}$ September 2018, Accepted: $11^{\text {th }}$ October 2018, Published: $31^{\text {st }}$ October 2018}

\begin{abstract}
The purpose of this study is to identify the level of job burnout amongst the IT employees working in a leading IT company in central India. Broadly, there are three areas of job burnout namely; emotional exhaustion, depersonalization and personal accomplishment. Maslach job burnout inventory is used to measure job burnout among employees of the organization under study. Job burnout scores of respondents across employees of various gender, age-group, job-grade were calculated. Average number of hours an employee is spending in office are also considered for the study. Based on abov3e categorization, employees were grouped and relevant statistical tests were applied to check if there is any significant statistical difference in job burnout scores of the employees under study. It was found that age, job grade and number hour's spent in office impact job burnout tendency while gender doesn't seem to have any impact on the same.
\end{abstract}

\section{Keywords}

Job Burnout, IT Employees, Maslach Job Burnout Inventory

\section{Introduction}

The wear and tear that a job does to the employee is often called as job burnout. There are multiple reasons for job burnout which can be associated right from personal to the organization. It is often called as a stress arising out of job. There are so many employees who have various dreams and aspirations with respect to their careers. Job burnout can be explained further as the emotional, physical or mental tiredness or exhaustion which affects the employee and his work. The IT industry is known to have employees who have to work for hours together at the computers or laptops and have got a strenuous work schedule. They also have extended working hours if required, of course, with weekends off. But still the work schedules are going to be more hectic as they have a sitting job as well.

There are generally three areas of job burnout that the employees can suffer from.

\section{- Emotional Exhaustion:}

It means the mental exhaustion arising out of job due to extra or tedious work. Employees having emotional exhaustion are those who generally feel that they are used at work completely. With this thought in the mind and the climate of organization, it may result to emotional exhaustion. The after effects of emotional exhaustion will be feeling tired, depressed and having low energy and vigor. These employees may start labelling themselves as those who won't be able to grow and would continue at the same level which gives further dissatisfaction. The employees facing this type of burnout will generally be involved in multiple tasks and projects simultaneously. The tasks and assignments may vary according to the involvement and may not be hectic every day.

\section{- Depersonalization:}

It is actually a side effect of job burnout wherein the employee will distance oneself from others and would like to stay alone. It can also be defined as voluntary withdrawal from colleagues and others at workplace. The reason for withdrawal is generally a lot of work pressure which results in aloofness. There are many cases specifically in the field of business development or sales wherein they meet a lot of clients and customers which also involves a lot of communication. The result is that they do not feel like communicating with others thereby staying aloof from others. The stress can come from immediate boss, clients, peer or otherwise in this category of job burnout.

\section{- Personal Accomplishment:}

By the term personal accomplishment we mean the feeling that we have achieved something that is important and of high relevance in one's career. This feeling comes in when one knows that he / she has contributed toward the job, department or organization in a constructive way. If the employee feels that his / her actions are aligned with the goal and vision of the company, it leads to a sense of achievement and accomplishment. However, if anything happens in the contrary, one may feel burnout. In other words, if the employees are not able to align their work with that of the organization, it may lead to a high burnout in the area of personal accomplishment.

There are varied personalities in the organization which are present at the workplace. Each employee has their own style of working. Some may be perfect and at the same time others may have a relaxed personality with respect to 
systems and processes. Some of the common behaviors and traits which IT employees have and may result in job burnout are as under:

- A perfectionist may always feel to do things in the best way and if it does not happen the expected way, it may lead to job burnout.

- Low confidence on self may also lead to job burnout

- Culture of grapevine communication

- Over concern for things, people and self

- Continuing pressures at job

- Feeling of exhilaration and not getting the response for the same

\section{Materials and Methods}

The primary data was collected through job burnout inventory from Public Welfare, Vol. 39, No. 1, 1981, American Public Welfare Association has been used which consisted of 25 statements and information related to demographics. The universe of respondents under study is employees of IT Company in central India selected for study. The sampling method used was simple random sampling and convenience sampling. However enough care has been taken sample represents respondents of all gender, age groups and job grades. Overall responses of around 180 employees were collected but responses from certain respondents were not considered due to incomplete responses or other discrepancies resulting in total 169 responses for study purpose.

Following hypotheses were framed based on gender, age groups, job grades and number of hours employee work daily.

H1: There is significant difference between job burnout score among respondents both genders.

$\mathrm{H} 2$ : There is significant difference between job burnout score among respondents of various age groups.

H3: There is significant difference between job burnout score among employees of various job grades.

H4: There is significant difference between job burnout score among employees working for different number of hours daily.

To test the hypothesis under study, ANOVA and t-test were applied using SPSS version18.0. Both the tests are used to check that whether there is any significant (statistical) difference in scores, results or responses among two or more groups under study.

\section{Results and Discussion}

The responses were recorded and coded for running statistical tests. The results of the tests are as follows

\section{Relation Between Job Burnout and Gender}

The job burnout score was calculated using a job burnout inventory and then its relation with respect to gender was studied using independent sample t-test. The confidence level was assumed to be $95 \%$ with $5 \%$ margin of error. The results of the statistical test are as follows

\section{Group Statistics}

\begin{tabular}{|cl|l|l|l|l|}
\hline Gender & N & Mean & Std. Deviation & Std. Error Mean \\
\hline Burnout_score & Male & 71 & 49.7042 & 14.72354 & 1.74736 \\
& Female & 98 & 52.5714 & 13.92173 & 1.40631 \\
\hline
\end{tabular}

Independent Samples Test

\begin{tabular}{|c|c|c|c|c|c|}
\hline & \multicolumn{2}{|c|}{ Levene's Test for Equality of Variances } & \multicolumn{2}{|c|}{ t-test for Equality of Means } \\
\hline & & $\mathrm{F}$ & Sig. & $\mathrm{t}$ & df \\
\hline Burnout_score & $\begin{array}{ll}\text { Equal variances } \\
\text { assumed } \\
\text { Equal variances } \\
\text { not assumed }\end{array}$ & 1.677 & .197 & $\begin{array}{l}-1.290 \\
-1.278\end{array}$ & $\begin{array}{l}167 \\
145.882\end{array}$ \\
\hline
\end{tabular}

Independent Samples Test

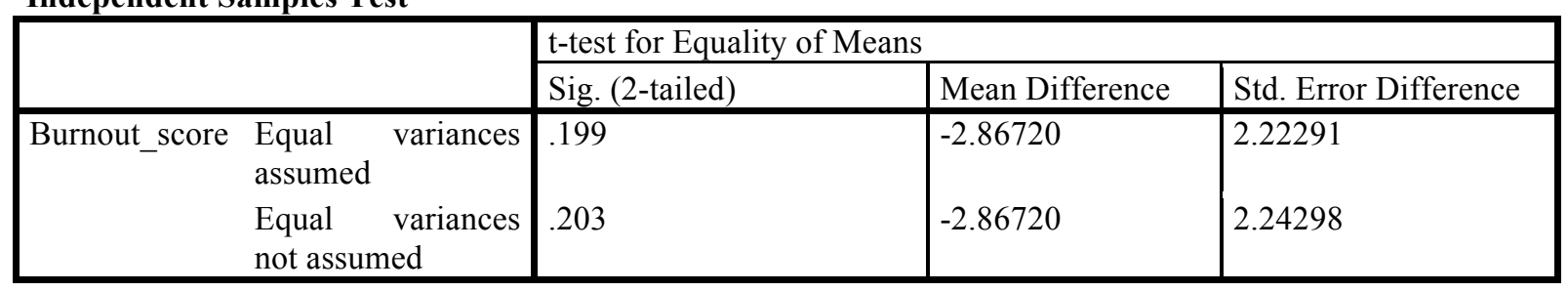


Since the significance value is less than 0.05 , it can be concluded that these is no significant difference in burnout tendencies among males and females. The responses collected are respected in graphically below.

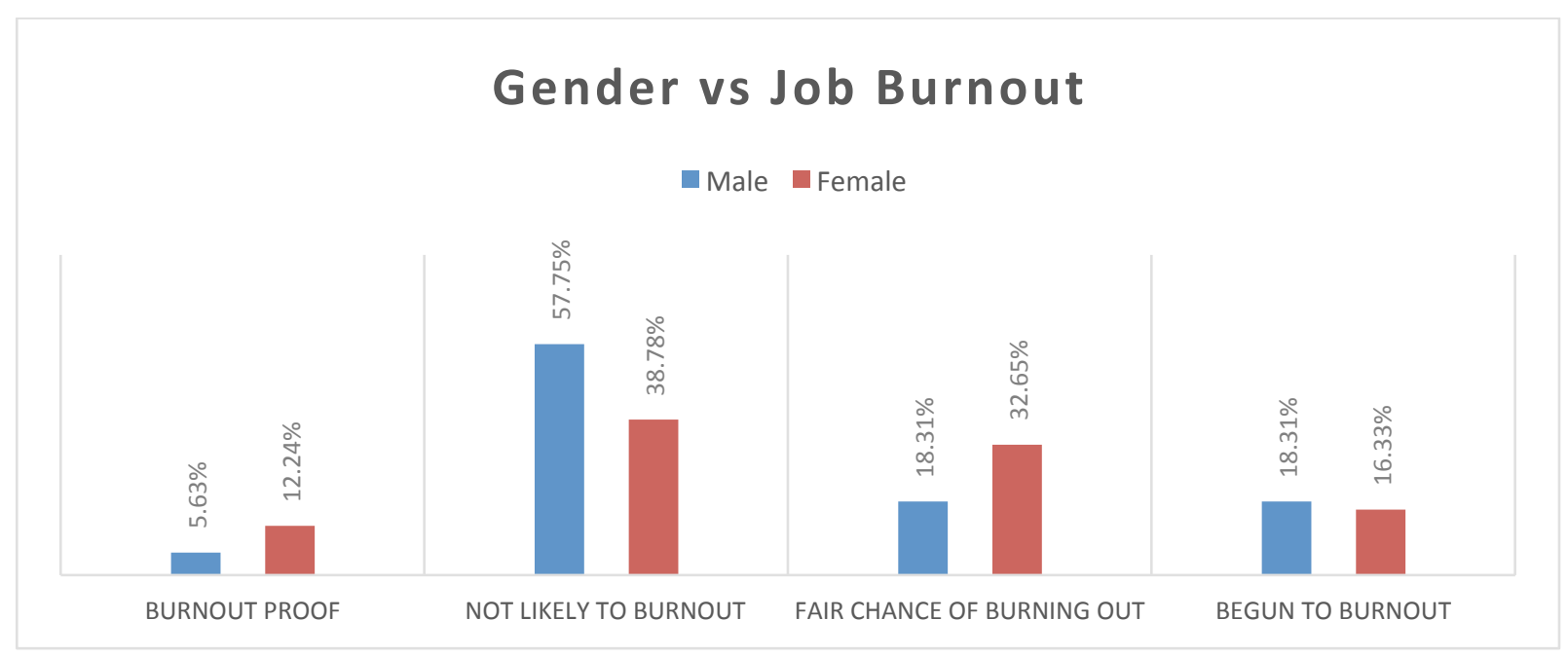

Relation Between Job burnout and Respondents of Various Age Groups

The respondents were divided into various age groups and job burnout score calculated for respective respondent. The graphical summary of data is shown below.

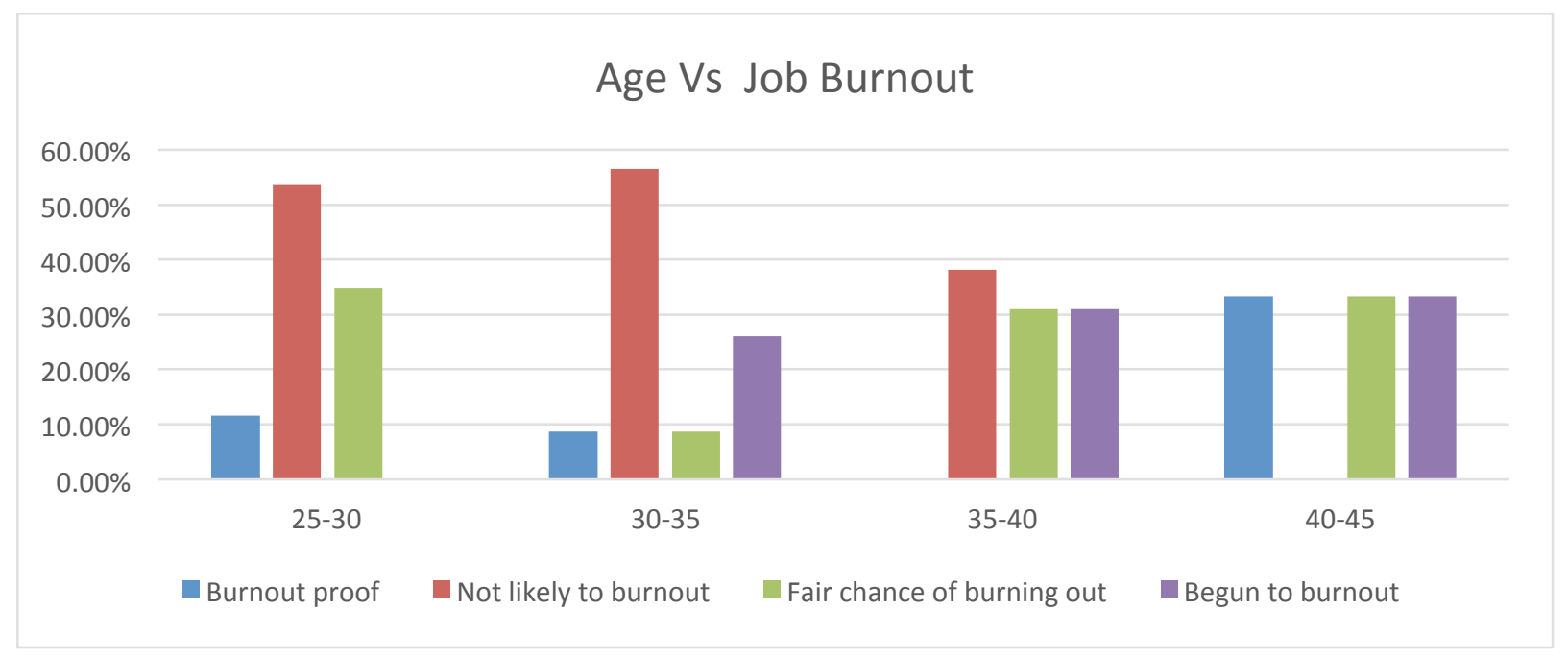

Statistical test - ANOVA was applied on the data to check if there is any significant difference between job burnout scores of various age groups. The results of the test are as follows

ANOVA

Burnout score

\begin{tabular}{|l|l|l|l|l|l|}
\hline & Sum of Squares & df & Mean Square & F & Sig. \\
\hline Between Groups & 4188.959 & 3 & 1396.320 & 7.648 & .000 \\
Within Groups & 30124.295 & 165 & 182.571 & & \\
Total & 34313.254 & 168 & & & \\
\hline
\end{tabular}

Since the significance value is less than 0.05 it is evident that there is significant difference between job burnout scores among respondents of various groups. From the graph and weighted average scores of job burnout it is evident that job burnout is increasing with increase in age. 


\section{Relation Between Job burnout and Respondents of Various Job Grades}

The respondents were divided according to their job grade or seniority in the organization under study and job burnout score calculated for respective respondent. Junior most employees are coded as 1 and senior most as 5 and remaining employees in-between accordingly. The graphical summary of data is shown below.

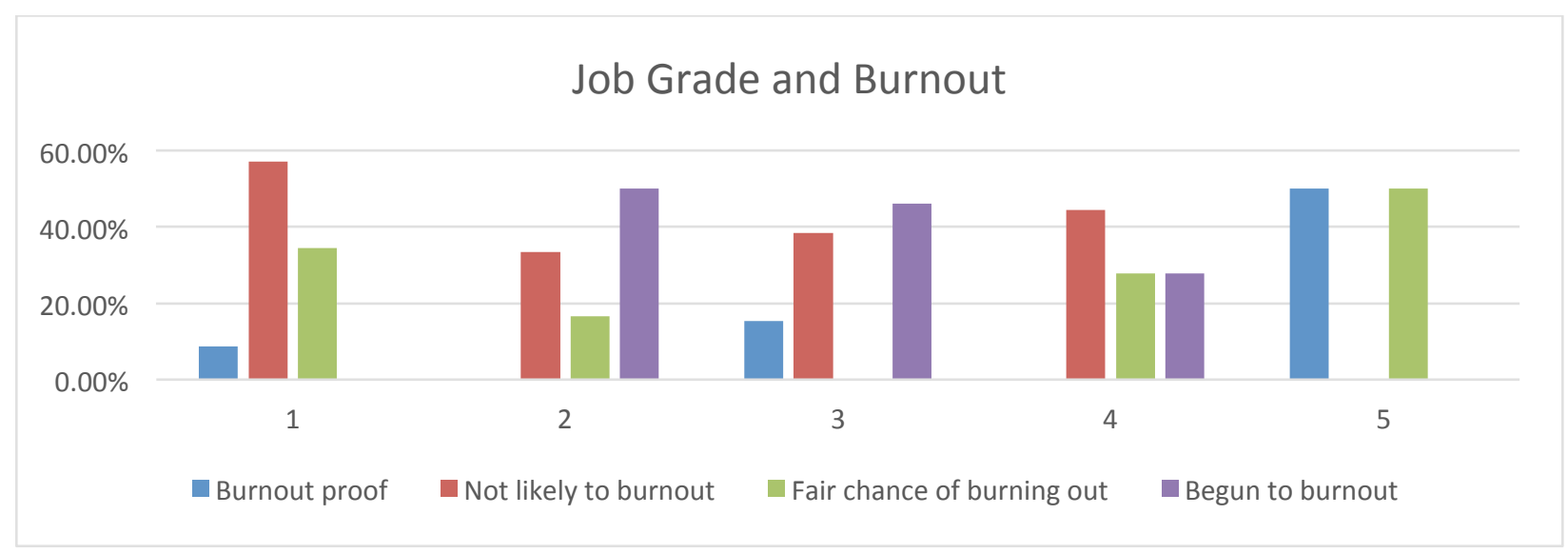

Statistical test - ANOVA was applied on the data to check if there is any significant difference between job burnout scores of employees of various job grades. The results of the test are as follows

ANOVA

Burnout score

\begin{tabular}{|l|l|l|l|l|l|}
\hline & Sum of Squares & df & Mean Square & F & Sig. \\
\hline Between Groups & 6110.472 & 4 & 1527.618 & 8.883 & .000 \\
Within Groups & 28202.783 & 164 & 171.968 & & \\
Total & 34313.254 & 168 & & & \\
\hline
\end{tabular}

Since the significance value is less than 0.05 , we can conclude that there is significant difference in job burnout tendency among respondents of different job grades. From graph and weighted average score of job burnout it is evident that mid -grade employees are more likely to burnout as compared to highest and lowest level employees.

\section{Relation Between Job burnout and Working Hours}

The respondents were asked about number of hours they work daily (on an average) and job burnout score calculated for respective respondent. The graphical summary of data is shown below

\section{Working Hours Vs Burnout}

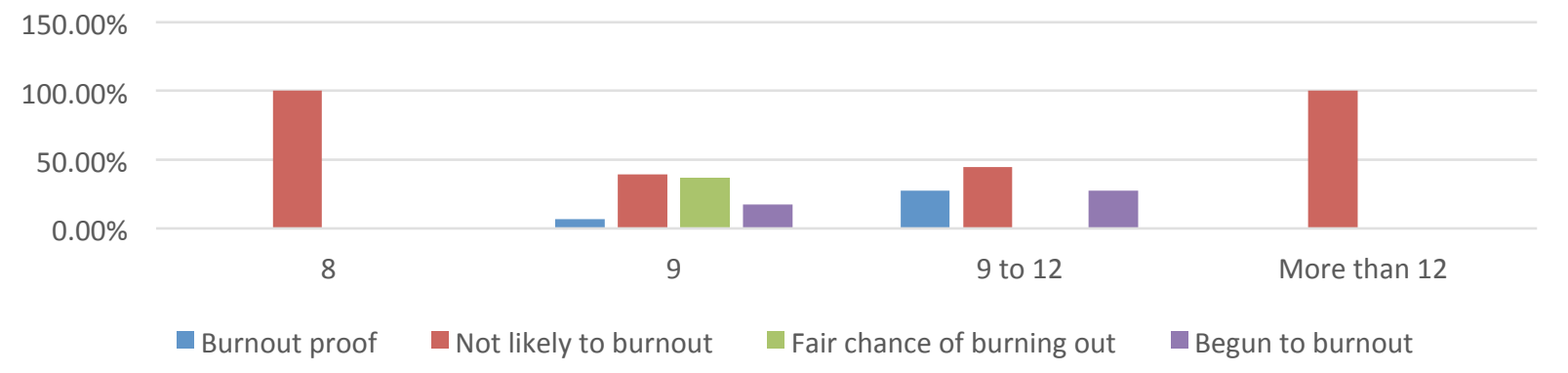

Statistical test - ANOVA was applied on the data to check if there is any significant difference between job burnout scores of employees spending different amount of time in office. The results of the test are as follows 
ANOVA

Burnout score

\begin{tabular}{|l|l|l|l|l|l|}
\hline & Sum of Squares & df & Mean Square & F & Sig. \\
\hline Between Groups & 2355.300 & 3 & 785.100 & 4.053 & .008 \\
Within Groups & 31957.954 & 165 & 193.685 & & \\
Total & 34313.254 & 168 & & & \\
\hline
\end{tabular}

Since the significance value is less than 0.05 , hence there is significant difference in job burnout tendency among employees working for different number of hours. From graph and weighted average score of job burnout it is evident employees who strictly adhering to work hours are less likely to face burnout. Interestingly, employees who are spending 12 hours for more on average are also less likely to face burnout, however, reasons for the same are beyond scope of this study and further study needs to be done to find out reasons for the same.

\section{Conclusion}

From the study it is evident that job burnout tendency varies with age, job grade and amount of time an employee is spending in office. However, gender of employee doesn't seem to any impact on job burnout tendencies. However, it must be noted that this study is based on employees of single organization In IT domain in central India. Further studies can be done in organizations from other industries, organizations from other geographies and socio-cultural environment. Special care must be taken while extending findings of this study to organizations operating in different domain, geography etc.

\section{References}

1. Job burnout inventory from Public Welfare, Vol. 39, No. 1, 1981, American Public Welfare Association

2. Maslach, C. (2003). Job burnout: New directions in research and intervention. Current directions in psychological science, 12(5), 189-192

3. Lee, R. T., \& Ashforth, B. E. (1996). A meta-analytic examination of the correlates of the three dimensions of job burnout. Journal of applied Psychology, 81(2), 123

4. Maslach, C. (1978). Job burnout: How people cope. Public Welfare, 36(2), 56-58'

5. Lee, R. T., \& Ashforth, B. E. (1996). A meta-analytic examination of the correlates of the three dimensions of job burnout. Journal of applied Psychology, 81(2), 123

6. Swider, B. W., \& Zimmerman, R. D. (2010). Born to burnout: A meta-analytic path model of personality, job burnout, and work outcomes. Journal of Vocational Behavior, 76(3), 487-506

7. Reichel, A., \& Neumann, Y. (1993). Work stress, job burnout, and work outcomes in a turbulent environment: The case of Israeli executives. International Studies of Management \& Organization, 23(3), 75-96

8. Cordes, C. L., \& Dougherty, T. W. (1993). A review and an integration of research on job burnout. Academy of management review, 18(4), 621-656. 